\title{
Corporate social responsibility in state regulation of sustainable development
}

\author{
Elena Vorobey $^{1, *}$, Liudmila Belosluttceva ${ }^{1}$ and Olesya Fesenko ${ }^{1}$ \\ ${ }^{1}$ Sochi State University, Sovetskaya, 26A, 354000, Sochi, Russia
}

\begin{abstract}
The need of corporate social responsibility development is mostly explained with the fact that the states do not cope with the solution of problems of a social assistance of the population. But as the state undertakes all social burden of the population, the need for corporate social responsibility disappears. So, it is substantiate to adopt the other approach the importance to proceed from essence of society as certain social system system of people, their certain communities connected with each other by the public relations, and their interests. Stable, steady existence of this system is possible only at mutual adjustment of all its structural parts adjustment of mutual interests.
\end{abstract}

\section{Introduction}

The World Business Council for Sustainable Development has described Corporate social responsibility (CSR) as the business contribution to sustainable economic development. Building on a base of compliance with legislation and regulations, CSR typically includes "beyond law" commitments and activities pertaining to: corporate governance and ethics; health and safety; environmental stewardship; human rights (including core labor rights); sustainable development; conditions of work (including safety and health, hours of work, wages); industrial relations; community involvement, development and investment; involvement of and respect for diverse cultures and disadvantaged peoples; corporate philanthropy and employee volunteering; customer satisfaction and adherence to principles of fair competition; anti-bribery and anti-corruption measures; accountability, transparency and performance reporting; supplier relations, for both domestic and international supply chains. The doctrine of corporate social responsibility - as we know it now - was formed in the period of the late 60th - the beginning of the 70th years in the USA, Great Britain, Japan, Germany and other countries. Its main idea - business has to care not only for profit and tax payment to the state but also to divide with the state and society the responsibility for economic disparity and the aggravation of an ecological situation.

For the years of the development of this concept, the corporate social responsibility gradually gains character of the objective law, a form theoretically and methodically developed system. The important feature of this development is the appearance of network of the national and international organizations of corporate social responsibility, such as

\footnotetext{
*Corresponding author: vorobei.sochi@yandex.ru
} 
"Business for corporate social responsibility", "Global Alliance", "The UN Global Compact", "The International Business Forum of Leaders", "CSP-Europe", etc.

\section{Methods}

Corporate social responsibility is known by a number of other names. These include corporate responsibility, corporate accountability, corporate ethics, corporate citizenship or stewardship, responsible entrepreneurship, and "triple bottom line," to name just a few. As CSR issues become increasingly integrated into modern business practices, there is a trend towards referring to it as "responsible competitiveness" or "corporate sustainability."

A key point to note is that CSR is an evolving concept that currently does not have a universally accepted definition. Generally, CSR is understood to be the way firms integrate social, environmental and economic concerns into their values, culture, decision making, strategy and operations in a transparent and accountable manner, and thereby establish better practices within the firm, create wealth and improve society.

The general theoretical and methodological basis of the corporate social responsibility research is the analysis of the human activity philosophical constants - freedom, freedom and responsibility, free will and human rights.

The methods used for this research paper are analysis, synthesis, comparison, classification, and grouping.

\section{Results}

Corporate social responsibility allows developing, on the one hand, a human and social capital "for today" and "on perspective", and, on the other hand, making a notable contribution to the solution of problems of social justice as factor of stability and stable development of society in general, strengthening thereby own social base of business - the authority among the population, and trust to business. Besides, social justice does not contradict the competition and, in general, a competition of individuals.

In a broad sense, the corporate social responsibility is the whole responsibility of corporations within the activity - responsibility for quality of production, tax payment, etc., i.e. this responsibility covers also economic and legal responsibility to the state. Strictly speaking, it is the social responsibility mediated by the state. In applicable sense the corporate social responsibility of corporations covers their direct corporate social responsibility - for the quality of life of society, for all the spheres of social life - education, health care, reproduction, ecological protection and so on.

The development of the international and national standards of the reporting on corporate social responsibility of corporations is another important feature. This fact demonstrates aspiration of the business companies to openness of the social policy. According to social reports, it is possible to judge how the world business progressed in social responsibility development. Corporate social responsibility is more and more realized by business as social need. Its purposes, organizational bases and practical actions are theoretically comprehended. And its understanding, at least, at progressively conceiving pioneers of business, acts in the form of the law of social development. It cannot be ignored in rescue of stable development of the business, and, eventually, the society.

\section{Discussion}

"Social responsibility is the responsibility of an organisation for the impacts of its decisions and activities on society and the environment through transparent and ethical behavior that 
is consistent with sustainable development and the welfare of society; takes into account the expectations of stakeholders; is in compliance with applicable law and consistent with international norms of behavior; and is integrated throughout the organisation." - Working definition, ISO 26000 Working Group on Social Responsibility, Sydney, February 2007.

Responsibility, as well as freedom, is the result of cognition of need. In addition to traditionally allocated two modalities of freedom, responsibility and free will, their third modality is connected with definition of limits or measures of the subject activity (the state or business) regarding transformation of the natural and social environment. Excess of this limits leads to the various deformations of conditions of development of social system in general. The main idea of the philosophical analysis of corporate social responsibility is that it acts as an important structural element within the wide regularity of the modern society development reflected in the concepts of "the social state" and "the social state economy".

The main social and economic principle of the social state is concluded in its social policy motivation. The state is not the favorable philanthropist (misanthrope) distributing tips from time to time to the poor and not the avaricious financier, financing the social sphere by the residual principle. It is, in some way, the prudent businessman knowing that the money invested into the human capital will return a hundredfold. And moreover, will return in the form of strengthening of the social stability, humanity, mutual responsibility. The social state is in this matter not the philanthropist, but the investor. The same way, the socially responsible business company is not the philanthropist, but the investor for the own hired personnel (to increase professional qualification and so far) and the social environment where the company works (forming the human and social capital, increase in purchasing demand, etc.).

The theory of the social state economy is submitted in various ways. Three main type of social state economy are distinguished. The so called Anglo-Saxon type is implemented in Great Britain, Canada, Ireland. Close to this type is the USA. The Western European continental type is presented by Germany, France, Austria, Belgium, the Netherlands. The Scandinavian type is developed in Sweden, Norway, Denmark, Finland.

Features of the first type are the following: the low level of the state participation in the solution of the social problems of society (such as unemployment, pension provision, etc.) and the strong private sector development rendering services to solve the social problems. The countries of this type are characterized by rather small part of GDP redistributed through the state budget (about 30-40\%).

Features of the second type are the achievement of high living standards with the active participation of the state with the effective programs for providing a high level of employment, social insurance for citizens, etc. Rather big part of GDP is redistributed through the state budget (nearly a half of GDP). Practice when major companies assume the decision on creation of system of pension and medical support of the workers, granting high grants at dismissal, creation of good working conditions and rest, the organization of protection of the environment is encouraged. The economy in general is guided by stable moderate growth. The separate firm is estimated both on profitability level, and on social indicators.

Feature of the third model - the high level of living of the population. High taxes are imposed. More than a half of GDP is redistributed through the budget. Special attention is paid on achievement of social partnership. The strong policy of alignment of the income is pursued. The share of taxes in GDP in general is rather higher in comparison with the countries of the first and second types of the social state economy.

The ideological and thematic similarity of the purposes and tasks of all three theories corporate social responsibility, the social state, social state economy is easily identified. Actually, the economy and the state everywhere and always, anyway - directly or indirectlyare focused on fulfillment of social needs of people (in food, clothes, home, reproduction, 
etc). In the process of public labor division there was the isolation of an economy from other spheres of public life - social, political and legal, spiritual and cultural. And, other side, the isolation of these last ones from economy. Therefore the problem of substantial superiority was acquired. Traditionally accrued together with political economy status of the main factor was assigned to economy. The absolutization of the role of economy resulted in the leading role of economy and all other spheres fell into the subordinated state - development of policy, rights, moral, art, religions, etc. subordinated to requirements and interests of economy development.

As a result of such state of art in science and practice, first of all, the social sphere was damaged. If economy is the sphere of production of means of life, then the social sphere is the productions of the life itself. This is not work in its economic form of obligatory need of production of means of life, but work as social concept and freedom phenomena. Exactly in the social sphere of life the highest humanistic relations - human rights, social environment, associations, friendship, love - are formed. And, of course, the economy is responsible for this, social life.

Researchers and politicians - "inventors" of the concepts of "social state" and "social state economy" are seeking now the ways to improve the situation, emphasizing the importance of the social sphere of public life.

Corporate social responsibility is a natural element of turn of classical capitalism towards social and fair society. Practice of this responsibility significantly concretizes contents of theories of the social state and social state economy. Regarding the theory of the social state especially, it should be noted that it not only takes away a considerable part of GDP on social needs, but by means of the legislation creates the legal system encouraging corporate business directly to participate in social development of the country - providing social support for citizens and ensuring stable, steady evolution of society.

The modern system of corporate social responsibility represents the final stage of evolution of traditional forms of charity - patronage, mercy, sponsorship. It gets an institutional form of natural activity of corporations in the conditions of completion of the industrial society development and its transition to a post-industrial stage. Formation of social programs, official standards and the reporting under development of the corporate social responsibility becomes its typical features.

The corporate social responsibility system is characterized by complex-level structure. Its first level (empirically basic) is made by corporations as really economic entities (micro and macroeconomics). The second level is presented by corporate social responsibility itself where business in general acts as the engine of civilization evolution of an existing historical form of society, regarding not only the development of its productive forces, but also the solution of environmental problems, and formation of new, higher standards of living. The third level is the national corporate social responsibility. At all ambition of business to globalization of interests and flattening of nations distinctions as steady forms of the humankind civilization coexistence, in general, it is subordinated to objective logic of development of the nations, the national states, realization of their national interests, acting as one of the main regulators of their social responsibility over each other for the general progress of humankind.

Social responsibility becomes crucial as the key decisions (laws and other acts) of a sociopolitical, legal and economic order, societies, obligatory for all members are made by the state. It concerns the freedom, responsibility, free will, the civil rights and duties. At the levels of regions, areas, corporations these decisions can be supplemented and concretized. Along with actually corporate elements, the corporate social responsibility elements could be defined as the corporations' owners represent the ruling business elite. Other words, the top management of corporations, developing corporate social responsibility, works not only for own corporation benefit, but also for the economic benefit of all owners. 
Over the time trends is, undoubted, the core concept of UN GC - implementation of its ten universal principals in the countries all over the world. Since the Global Compact was formed at the headquarters of the United Nations in July 2000, it is now made up of thousands of participants from over 100 countries and has become the largest and most important corporate citizenship and sustainability initiative in the world.

The practical side of the process in the Russian Federation shows the positive dynamics of the UN Global Compact principles implementation.

Global Compact was officially presented in Russia in 2001. In 2008, participants of the Global Compact Network Russia (UNGC, Russia) carried out important structural and organizational changes, aimed to increase the effectiveness of the Russian local network's activities. The Steering Committee of the UNGC, Russia in January 2009 signed memorandum about the mutual understanding between the UNGC, Russia and the Global Compact office in New York. In 2011 the Russian Network was invited to participate in Global Compact LEAD and in 2012 the Russian Network representative was invited to participate in Global Compact Board. The effectiveness of the work is proved by growing number of participants year by year.

Ministry for Foreign Affairs of the Russian Federation marks achievements of the Global Compact Network Russia and considers the importance of continuing the work together for its development. S.V. Lavrov paid special attention to the importance of promoting the UN Global Compact principles and values in Russia. "In general, the Ministry for Foreign Affairs of the Russian Federation supports effort aimed at promotion of sustainable development principles in our country, expansion of cooperation between the Russian private sector and non-governmental organizations and the UN agencies within the framework of the Global Agreement on common values and principles..., - the minister said. - For 15 years, this initiative has become a leading multilateral dialogue platform and a key mechanism in the promotion of corporate social responsibility principles".

It was proposed to carry out examination of the UN Guiding Principles on Business and Human Rights in relation to the Russian legislation, analyze public opinion, and launch the partnership education program as well pay special attention to the resumption of collaboration on implementation of the public non-financial reporting in the Russian Federation. Special attention is paid to the fact that integration of the UN Global Compact principles into the corporate system of values is a recognized indicator of responsible business practice, necessary for getting access to the international level of activity and partnership, effective and fair way to minimize risks and monetize respectable reputation.

The Global Compact Network Russia round table dedicated to the development of the inter-agency action plan for implementation of the UN Guiding Principles on Business and Human Rights outlined the main directives for the Working Group:

- to carry out examination of the UN Guiding Principles on Business and Human Rights in relation to the Russian legislation;

- to summarize international experience in development of the national plans for the Guiding Principles implementation, offering the country format of the document;

- to analyze public opinion and implement the partnership education program on the subject;

- to form the position of the Global Compact Network Russia in terms of protection of the rights of indigenous peoples of Russia;

- to pay special attention to the resumption of collaboration with the Ministry for Economic Development on implementation of the public non-financial reporting in the Russian Federation.

It should be also mentioned that the Global Compact Network Russia has been closely involved in drafting of the UN Guiding Principles on Business and Human Rights document, 
organized its translation into Russian language and contributes to promotion of the Guiding Principles in the Russian Federation.

According to the 2016 PwC Global CEO survey, 64\% of CEOs say that "CSR is core to their business rather than being a stand-alone program" and increase investment in corporate social responsibility because they care about building trust with consumers, partners, governments, and their employees.

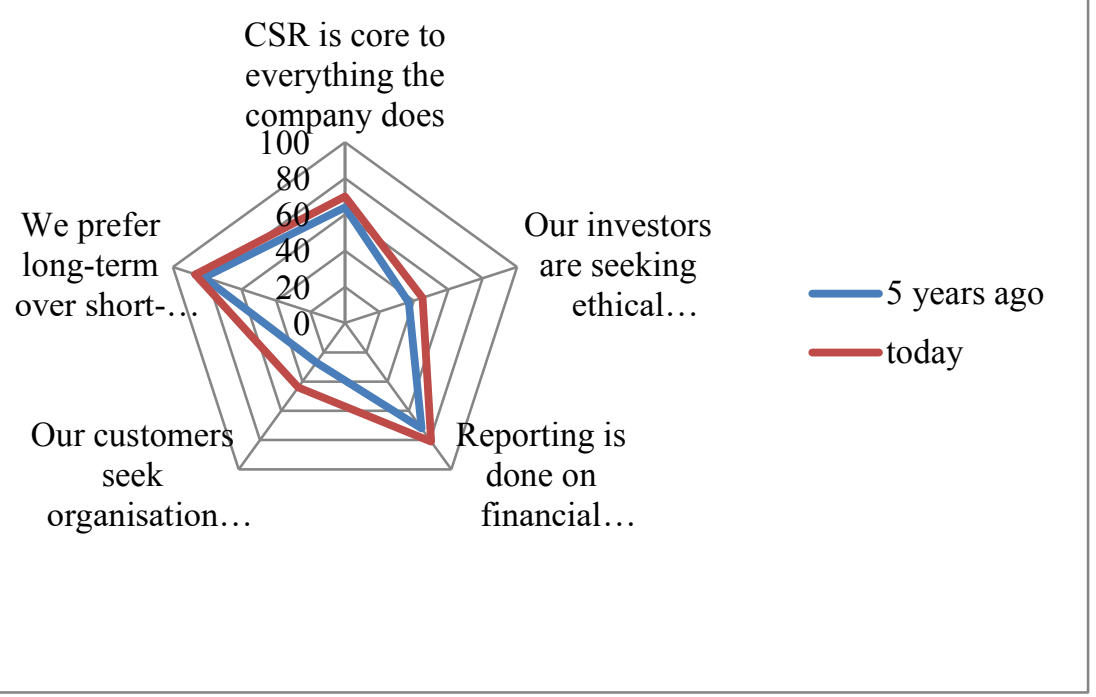

Fig. 1. CEOs' CSR impact estimation (\%).

The Ethical Corporation recently released a report in which research from 948 CSR professionals from around the globe on their thoughts of the state of their profession as it moves into 2017 are gathered. One of the biggest contemporary focuses for companies is improving their CSR in terms of tailored goals, visibility, reporting, and more. CSR experts contribute with their input on how the current situation will impact corporate sustainability, what trends will emerge in 2017 and how the industry will continue to evolve. On this basis of what was most crucial for companies to deal with CSR the trends for the companies in 2017 were developed. So, here are the main CSR 2017 trends:

CSR becomes more mainstreaming, which means more competition. A few years ago, it was enough for companies to have a comprehensive CSR section on their website, with a simple description of how they took into consideration the environment, communities, and their social impact. An imprecise understanding of social impact is no longer enough to stand out amongst the top public companies with the best CSR reputations. Taking action against climate change, contributing to social justice movements, and standing firm in founding principles are trends in themselves for not only big, but also medium-size and small companies, and have become not just acceptable, but expected. With more companies understanding the value CSR can bring to both their public image and their stakeholders, it's getting harder to make a message stand out in a rapidly growing number of 'good-doing' companies.

CSR content will become more personalized. Focus on CSR goals that make sense for your company and will garner the most trust from your primary stakeholders. A trap that many companies fall into is thinking that CSR is only about giving back to the environment. CSR can also focus on efforts with local communities and interactions with your own consumers and what matters to them. Building investor trust means tailoring content to their 
main concerns, while also ensuring you're staying true to your company's story and goals. If the multiple CSR success stories to a company newsletter are published, one focusing on community impact and one focusing on social change, it can serve different content to different investors based on what they most care about. Investors are looking for more personalized content, and this includes what CSR stories should be promoting.

Showcase CSR efforts through video and animation. Perhaps the biggest trend seen year by year in the digital marketing world is that the online attention span of consumers is shrinking astronomically, as information is used to be got online right away, in bite-sized pieces. The same concept applies with investors. Investors won't have the time to read a 15 page report on how the latest CSR measure impacted a community and benefited the company. CSR successes of the past year should be broke down with videos, data visualizations, or animations on the website. Even more important: reporting must to be shareable. Short videos illustrating the impact as a company are the perfect way to get some brand differentiation and easily circulate the message.

Aligning the CSR goals with those at the top. Ethical Corporation's report states that "Only 25\% of CSR executives stated their CFO is absolutely convinced of the value of the CSR report". This is a problem. If the company's CEO, CFO, and more aren't aware of the CSR goals for the coming year, or don't see value in spending more time, energy, and money on CSR initiatives or CSR reporting, the company will come across as disjointed and not united in your social message. Ensure that environmental impact, social justice, and community service goals aren't simply dreamt and executed within one department. The whole company, from the top to the bottom, should understand the importance of what is doing and how it relates to the vision and the goals.

Availability of CSR presentations on every platform. Translating of the CSR initiatives to video and animation is important, but it's equally important to make sure what is put out there and how it can be accessed by anyone who wants to see what your company is up to. 2017 will see even more people disregard their desktops for a mobile phone, so it is needed to make sure every downloadable CSR presentation, testimonial video, customer story, and website link are available by a smartphone or tablet browser.

Not just report, but back relating. Ethical Corporation's report says, " $60 \%$ of respondents agreed that too much time is being spent on the reporting process". Investors want to see how CSR initiatives affected the numbers. It is time to think about other ways to illustrate the impact been made. To include more employee testimonials, customer success stories, environmental impact studies, or 'Message from the CEO' videos. Mixing up how to deliver CSR good news makes sure investors, as well as target audiences.

Corporate social responsibility acts as an essential part of the general process of harmonization of the public relations. The important factor of the theory and practice of corporate social responsibility development is not only its own evolution as economic institute, but its interaction with the social movement of civil society. The corporate social responsibility development promotes the quality of life increase, civil rights and freedom.

\section{Conclusions}

It is necessary to recognize legitimacy of the concepts "social business" or "socially responsible business" - responsibility of business at the level of corporations as economic entities. It allows to develop the mechanism of the empirical measurement and control of their corporate social responsibility in corporations (in relation to own hired workers) and outside - to the population and the administrative authority of those territories in which their enterprises operates, and partly in the form of sponsorship of cultural institutions, education and so on. 
The same should be told about the nation. In spite of economic and political globalization, the humankind lives in national apartments in the state legal form of national associations national or multinational states. It means that corporate social responsibility has also the national form. Business corporations can successfully develop in transnational scale, developing corporate social responsibility for the benefit of states where they used to work. But anyway, in the obvious or latent form, these corporations remain providers of political and other interests of "mother country".

In business (political, economic, etc.) practice, a number of concepts was created to interpret "corporate social responsibility" as a gift, i.e. as business activity, first, outside actually economic sphere, and secondly, outside legally obligatory principles and norms. Business, on the one hand, is responsible over the state and builds the activity according to legal system of this state. But on the other hand, it is directly responsible over society and is forced to build the activity according to moral system of this society.

\section{References}

1. URL: www.forbes.com

2. M.V. Taganov, PhD Thesis, MSIU, Moscow, 2015)

3. G. Collins, Effective CSR Implementation (CIPS Knowledge, Stamford, 2013)

4. The UN Global Compact, Global Compact Network (2011)

5. URL: http://www.globalcompact.ru/events/mid-rf-otmechaet-dostizheniya-setiglobalnogo-dogovora-oon-v-rossii-i-schitaet-vazhnym-prodolzhit-so/ 